\title{
EDUCAÇÃO, MEIO AMBIENTE E CULTURA: ALQUIMIAS DO CONHECIMENTO NA SOCIEDADE DE CONTROLE
}

\author{
Ana Godoy* \\ Nildo Avelino**
}

RESUMO: Por meio da noção de regime pedagógico, investiga-se a articulação entre epistemologia e política em dois eixos de funcionamento: um em torno da disciplina corporal ligado às exigências do processo de industrialização, outro em torno da autonomia do sujeito ligado à formação dos Estados nacionais. Os historiadores da educação situaram no coração das práticas escolares a inscrição pedagógica do cidadão como sujeito político dotado de direitos e obrigações; essa inscrição respondeu às exigências inerentes ao quadro conceitual próprio das sociedades democráticas. A noção de alquimia, proposta por Popkewitz, foi retomada para compreender como as práticas pedagógicas traduzem saberes disciplinares em conteúdos psicológicos que são inseparáveis de contextos políticos mais amplos; esse aspecto confere à pedagogia uma dimensão estratégica que deve ser levada em conta na análise dos investimentos pedagógicos no presente. Considerando as características que atravessam as práticas sociais de nossos dias, a intervenção de tipo ambiental (Foucault) e a lógica do controle (Deleuze), são abordados Educação, Meio Ambiente e Cultura como domínios de objetos sobre os quais atua o investimento pedagógico hoje.

Palavras-chave: Educação; Meio Ambiente; Cultura.

\section{EDUCATION, ENVIRONMENTAL AND CULTURE:}

\section{ALCHEMICAL OF KNOWLEDGE IN THE CONTROL SOCIETY}

ABSTRACT: Through the notion of pedagogic regime, we investigate the articulation between epistemology and politics in two operational axes: one concerning the body discipline related to the needs of the industrialization process, the other concerning the subject's autonomy related to the formation of the national States. Educational historians set, on the core of school practices, the citizen's pedagogic inscription as a political citizen endowed with rights and obligations; this inscription responded to the inherent

\footnotetext{
* Pós-Doutora em Educação pela Universidade Estadual de Campinas (UNICAMP); Pesquisadora na área de Política da Educação no Centro de Cultura Social. E-mail: anadgp@uol.com.br

** Pós-Doutorando em História no Programa de Pós-Graduação em História da Universidade Estadual de Campinas (UNICAMP); Bolsista da Fundação de Amparo à Pesquisa do Estado de São Paulo (FAPESP); Pesquisador no MoDys-Monds et Dynamiques des Sociétés (www.modys.fr) e Pesquisador na área de Teoria Política no Centro de Cultura Social. E-mail:nildoavelino@gmail.com
} 
demands of the democratic societies' own conceptual perspectives. The alchemy notion, proposed by Popkewitz, was used to comprehend how pedagogic practices translate discipline knowledge into psychological subjects inseparable from wider political contexts; such aspect offers the pedagogy a strategic dimension that must be considered when analyzing pedagogical investments in present-days. Considering the characteristics that go through current social practices, the sort of environmental intervention (Foucault) and the logic of control (Deleuze), Education, Environment and Culture, are approached as domains of objects upon which pedagogical investments are carried out nowadays.

Keywords: Education; Environment; Culture.

\section{Introdução}

A pedagogia, diz Popkewitz (1997, p. 18), não é simplesmente aquilo que ela diz sobre o mundo; constitui também uma disciplina de práticas socialmente construídas e politicamente inseridas. Não seria possível, portanto, compreender regimes de práticas pedagógicas sem descrever o meio social, político e cultural em que funcionam. Ao contrário, sua inteligibilidade tornar-se-ia acessível somente quando correlacionados a outros regimes de práticas, tais como regimes econômicos, penais, morais, de racionalidades, etc. Por regime pedagógico é preciso entender o conjunto dos procedimentos e das instituições pelos quais os indivíduos encontram-se engajados e constrangidos a se vincularem com padrões cognitivos e motivacionais que são, por sua vez, associados e conectados a outros regimes de práticas econômicos, jurídicos, morais, etc. Dean (1999, p. 23) notou que um regime de práticas comporta ao menos quatro dimensões: 1) as formas de visibilidade; 2) as maneiras distintas de pensamento e procedimentos de produção da verdade; 3) os modos específicos de ação, intervenção e direção; e 4) os modos de formação de sujeitos. Estudar regimes pedagógicos implica compreender a maneira pela qual as ciências pedagógicas, através de procedimentos múltiplos e locais, "disciplinam a forma como o mundo deve ser visto, sentido e como se deve agir e falar sobre ele" (POPKEWITZ, 1997, p. 22), percebendo suas conexões com outros tipos de regimes. A análise de regimes pedagógicos supõe a não-separação, mas as conexões sempre existentes, entre epistemológico e político. Desse modo, tomando a definição que Popkewitz (1997, p. 23) deu da epistemologia como conjunto de regras e modelos "através dos quais o 
mundo é formado, as distinções e categorizações que organizam as percepções, as formas de responder ao mundo e o conceito do self", fica claro como a articulação entre político e epistemológico possibilita perceber como diferentes regimes implicam, necessariamente, um regime de verdades sobre os indivíduos, individualizando-os.

$\mathrm{Na}$ história do Ocidente, até a segunda metade do século XX, essa articulação entre política e epistemologia, implícita nas práticas pedagógicas, conheceu ao menos dois grandes eixos: um em torno da disciplina corporal ligado mais particularmente às exigências do processo de industrialização, outro em torno da autonomia do sujeito ligado à formação dos Estados nacionais.

\section{Educação e disciplina dos corpos}

Uma das primeiras tarefas que o processo de industrialização realizou, no final do século XVII, foi promover a racionalização do trabalho e das técnicas de produção. Para a instalação da indústria e para o estabelecimento do processo industrial foi preciso promover a passagem de uma economia rural, e em grande parte domiciliar, para o regime de fábrica. Uma das características fundamentais do trabalho domiciliar era a de não estabelecer cronogramas precisos, o que permitia ao trabalhador dedicar-se a grande variedade de tarefas que se intrincavam na sua rotina produtiva, demonstrando a continuidade entre cotidiano e ocupação, na qual o trabalho aparece como extensão da vida ordinária das pessoas. Isso era possível pelo caráter primordialmente irregular das ocupações e pelo controle que os indivíduos tinham do seu tempo, permitindo-lhes alternar momentos de trabalho intenso com momentos de ociosidade.

Todavia, esse traço comportava igualmente um sentido epistemológico do indivíduo bastante preciso. Como afirma Popkewitz (1997, p. 70), no século XVII e no início do século XVIII, o indivíduo era percebido como "irresponsável e indiferenciável", porque "relacionado com uma economia tradicional de subsistência, na qual a estrutura doméstica era a unidade de produção [e] o trabalho era diferenciado conforme as categorias coletivas mais do que pela habilidade ou interesse 
individual". A indústria defrontava-se, portanto, com a oposição cultural de "uma cultura tradicional que é, ao mesmo tempo, rebelde" e que "resiste, em nome do costume, às racionalizações e inovações da economia" (THOMPSON, 1998, p. 19). Foi preciso tornar o trabalho um hábito regular e contínuo, para isso o mercantilismo teve de justapor a essa cultura popular rebelde outra cultura, cujos valores estivessem ligados ao mundo do trabalho. Esse conflito explicita uma série de confrontos "entre uma economia de mercado inovadora e a economia moral da plebe" (THOMPSON, 1998, p. 21). Para produzir riquezas, o capitalismo precisou "produzir" um novo homem ligado ao aparelho de produção e disposto a transformar seu corpo em força de trabalho e seu tempo em tempo de trabalho.

Segundo Foucault (2002), para fazer do tempo e dos corpos dos homens algo que fosse força produtiva, foi necessário um conjunto de mecanismos de sequestro sistemático e contínuo dos indivíduos em instituições como a prisão, o hospital, a fábrica e a escola. Essas instituições, apesar de suas finalidades específicas, são atravessadas por uma característica comum: seu funcionamento "implica uma disciplina geral da existência que ultrapassa amplamente as suas finalidades aparentemente precisas" (FOUCAULT, 2002, p. 118). A fábrica fixa os indivíduos a um aparelho de produção, a escola fixa-os a um aparelho de transmissão do saber, o hospital e a prisão fixam-nos a um aparelho de correção; todavia, todas "têm como finalidade primeira fixar os indivíduos em um aparelho de normalização dos homens. (...) Trata-se de garantir a produção ou os produtores em função de uma determinada norma" (FOUCAULT, 2002, p. 114). Essas instituições formam uma rede de sequestro de corpos no interior da qual a existência dos indivíduos é encerrada com o objetivo deliberado de formar, reformar e corrigir comportamentos para a aquisição de aptidões e de certo número de qualidades, produzindo um corpo capaz de trabalhar. Por essa razão, são instituições que não se destinam simplesmente a garantir a execução de suas finalidades imediatas e de suas funções particulares. Não é suficiente, para os objetivos da indústria, que a escola exerça tão-somente a função de aprendizagem e ensino.

No século XVIII, até o final do século XIX, ao lado do cárcere, do hospital e da fábrica, a escola foi uma instituição austera. A pedagogia estava vinculada a um sistema externo de coerção através do qual as 
crianças eram treinadas por meio da repetição, do exercício e da ameaça da palmatória; os escolares deviam aprender os fatos, os preceitos morais e as rotinas da escola, por meio de um aprendizado que assumia as formas de uma atividade passiva (POPKEWITZ, 1997, p. 65). A educação funcionou como treinamento para adquirir o hábito do trabalho. A primeira regra que o estudante deveria aprender era a de dar novos ritmos ao seu corpo; uma vez na escola, a criança deveria habituar-se a uma estranha modelação corporal. Durante muito tempo, como observa Godoy (2008b), “alunos e professores, foram tornados aptos a um certo tipo de atletismo que, ao reduzir o movimento a intervalos de imobilidade submete os corpos sem dor e sujeita a vontade sem forçá-la". ${ }^{1}$ Todavia, a partir do fim do século XIX, a instrução evolui da exigência de simples repetição e, mitigando as coerções físicas, passa a induzir à obediência por meio de mecanismos de pressão social e psicológica.

\section{Educação e autonomia dos sujeitos}

Além do eixo disciplinar corporal, a pedagogia foi articulada a outra dimensão: a disciplina do eu sob a forma de subjetividades cidadãs. Após os movimentos da Revolução Francesa, a moral não se estabeleceria apenas no plano da inteligência e da memória, mas implicou também, como observou Procacci (1993, p. 242), um processo de educação dos pobres nos valores sociais burgueses do século XIX. A educação oferecia a ocasião irrecusável de intervenção sobre os indivíduos no momento mesmo em que se esboçava sua ignorância: a infância. Mas a educação deveria igualmente imaginar "um saber apropriado para 'simples operários' que, pensavam os economistas sociais, tinham por única necessidade saber ler, escrever e contar. Fora dessas poucas noções elementares, a escola deveria sobretudo servir para inculcar uma disciplina desde a mais tenra infância". Com isso, "a escola aparecia numa perspectiva ambientalista dos economistas sociais como meio potente de modificar o ambiente no qual os pobres viviam, e sua influência sobre eles" (PROCACCI, 1993, p. 243).

A partir desse processo de moralização, segundo Procacci, abriuse uma linha de intervenção específica pela constituição do cidadão como 
sujeito politicamente responsável e capacitado para participar nos processos de representação política. As sociedades liberais possuem a característica, resultado de seu quadro conceitual político, que exige tomar como referência o indivíduo na qualidade de sujeito autônomo e fonte do direito: o indivíduo não somente funda, mas delimita e estabelece as fronteiras para o exercício do poder político. Cruikshank (1999, p. 19) mostrou como a distinção feita por Tocqueville, em 1830, entre cidadãos e súditos servia de parâmetro crítico para separar as atividades e as qualidades do cidadão democrático de outras formas de ação política. Para Tocqueville, o cidadão autogovernado possui capacidade e poder para participar da política, para agir sobre seus interesses coletivos, desejos e objetivos. Dessa maneira, a noção de cidadania torna a sociedade governável de seu interior, provocando uma mutação de sentido na noção de liberdade do cidadão: ela se torna o resultado de um aprendizado da sociabilidade. Esboça-se um vasto projeto pedagógico que tem por objetivo formar cidadãos, o sujeito da sociedade civil, fazendo da sociabilidade individual o campo aberto e ilimitado de uma pedagogia que traz em seu núcleo a noção de dever, cujo objetivo é a formação de indivíduos portadores de cidadania, e a relação entre eles. $\mathrm{O}$ indivíduo será finalmente definido por seu "dever de ser cidadão", entendido no duplo sentido como sujeito político de direitos e como "elemento subjetivo de um sistema de deveres engendrados por suas relações com os outros" (PROCACCI, 1993, p. 307).

A noção de cidadania teve grande importância nas políticas escolares. Alimentada por uma necessidade inerente ao quadro conceitual das sociedades democráticas, os discursos acerca da formação do cidadão ganharam dimensão cada vez maior. A cidadania foi vista como única garantia contra as tendências despóticas do Estado, na medida em que residia nela a capacidade real de os indivíduos de governarem a si mesmos, interiorizando a própria natureza do poder democrático (PROCACCI, 1993, p. 311). A educação constituiu-se como via direta para o selfgovernment dos cidadãos, na direção de uma cidadania ativa. Tomando nossa contemporaneidade, Corrêa (2006, p. 58) mostrou como, no Brasil, nos anos 1940, Francisco Campos afirmava que a escola deveria integrar "no sentido orgânico e construtivo da coletividade, não se limitando ao simples fornecimento de conceitos e noções, mas abrangendo a formação dos novos cidadãos, de acordo com os verdadeiros interesses nacionais". 
Como indicaram os historiadores da educação, a inscrição pedagógica do cidadão nos indivíduos foi uma função importante e uma das principais características dos diversos regimes pedagógicos desde o final do século XVIII até os nossos dias. Popkewitz (2000; 2002; 2004) sugere que essa inscrição pedagógica pode ser compreendida contemporaneamente atuando como uma espécie de alquimia. Tomando os saberes da administração como práticas, Popkewitz (2000, p. 18) sugere que as teorias do Currículo podem ser pensadas como desempenhando uma função alquímica sobre saberes disciplinares, na medida em que transformam tradições intelectuais bastante específicas, de historiadores, físicos ou matemáticos, por exemplo, no interior de práticas pedagógicas. Ao considerar que os saberes envolvem não apenas relações institucionais particulares, mas também sistemas de racionalidade que dispõem sobre a pesquisa, o ensino e o estatuto profissional, ele evidencia como

a pedagogia escolar extraí continuamente sua existência ao mesmo tempo de dois espaços sociais. Um é o espaço disciplinar em que as produções da ordem interna do saber são criadas, sustentadas e transformadas. (...) $\mathrm{O}$ segundo espaço é o contexto cultural e político em que funciona a disciplina. Hoje, a produção do saber disciplinar ocorre em relação com constelações sociais e culturais particulares, tais como as agências estatais concernidas com questões de bem-estar sobre os efeitos da pobreza, as organizações filantrópicas que têm como "alvo" certas questões sociais e grupos na sociedade, as empresas comerciais interessadas em um certo consumismo etc. (POPKEWITS, 2000, p. 23)

A alquimia consiste em transferir a produção dos espaços sociais específicos da investigação disciplinar para o interior de práticas pedagógicas inseparáveis de contextos socioculturais mais amplos. Nesse movimento, a pedagogia promove a tradução dos temas disciplinares em conteúdos psicológicos. Os padrões de currículo da educação estão concernidos, fundamentalmente, "com crianças hábeis para pensar, para desenvolver habilidade em comunicação, para produzir um trabalho de qualidade e para realizar conexões com a comunidade" (POPKEWITZ, 2002, p. 262-263). Os padrões curriculares em educação utilizam uma terminologia que prescreve certo desenvolvimento cognitivo para a criança, através do qual ela se torna pessoa autônoma e responsável no aprendizado, na resolução de problemas e no processo reflexivo. 
Os princípios diretores da alquimia não se encontram na matemática ou na ciência, mas na pedagogia. (...) A alquimia é um item necessário da escolarização. (...) É alcançada através de um conjunto de dispositivos de inscrição que traduzem e ordenam sujeitos escolares. (...) Dispositivos de inscrição pedagógica que ordenam e classificam os objetos do ensino - as categorias que classificam o processo reflexivo da criança e a "natureza" do saber disciplinar organizado para a instrução. O que é significativo nesses dispositivos de inscrição é que eles tornam a reflexão da criança visível e passível de governo. A noção de governo utilizada aqui diz respeito a visualização e inscrição de distinções que classificam e ordenam a conduta da criança, sua ação e participação. "Resolução de problemas" é um dispositivo de inscrição que demarca, preserva e torna administrável aquilo que é percebido como caráter saliente, características e capacidades inatas de uma criança. (POPKEWITZ, 2004, p. 3)

Desse modo, como afirma Popkewitz, "o foco da inscrição psicológica recai sobre as disposições internas ou a alma da criança, produz a criança solucionadora-de-problema como um tipo humano para a intervenção pedagógica” (POPKEWITZ, 2004, p. 4). Os dispositivos de inscrição pedagógica incorporam princípios de normalização e divisão que implicam práticas de inclusão e exclusão social. Mapear a atividade da criança como solucionadora de problemas implica igualmente mapear indivíduos cujo comportamento não é o de um solucionador de problema, que serão inscritos como a criança menos desenvolvida.

\section{Problemáticas da educação hoje: meio ambiente e cultura}

Como observou Gallo (2003, p. 99), a educação é inseparável dos mecanismos de controle social que constituem o reverso da função manifestada pelo ensino. Implícito à formação do aluno, "há também funções latentes" de controle que se dão "nas ações mais insuspeitas". Então, tomando as práticas pedagógicas como dispositivos e estratégias, seria preciso questionar em quais domínios de objetos possíveis o investimento pedagógico atua no presente? A questão é pertinente quando consideradas as transformações ocorridas no pós-Segunda Guerra. Seria possível dizer que o tipo de experiência escolar descrita precedentemente esteve conectada e respondia àquilo que Foucault (2000) chamou de sociedade disciplinar, cuja preocupação maior recaía sobre o 
tratamento e a correção dos indivíduos, de modo a capacitá-los ao convívio social e ao trabalho útil. Entretanto, a partir dos anos 1980, esse ideal reabilitativo, vinculado a políticas de tratamento e correção, começa a ser substituído por objetivos de prevenção e intimidação de comportamentos. Outra característica das sociedades disciplinares é sua conexão com um processo de desenvolvimento industrial caracterizado pela carência de mão-de-obra e pela consequente inclusão massiva nos quadros regulares da indústria. Nas sociedades atuais, tem-se um regime produtivo de excedência e uma exclusão massiva dos quadros da indústria, sendo que o grande problema que se coloca é o do governo dessa excedência (DE GIORGI, 2002).

Não se trata do desaparecimento da disciplina. Todavia, como mostrou Foucault (2004a; 2004b), o horizonte de análise das sociedades atuais não é caracterizado mais por um projeto exaustivo de disciplinamento, que se prolongaria no interior de mecanismos através de uma rede de instituições normativas. Tem-se hoje

a imagem ou a idéia ou o tema-programa de uma sociedade na qual existiria a otimização dos sistemas de diferença, na qual seria deixado campo livre para os processos oscilatórios, na qual existiria uma tolerância acordada aos indivíduos e às práticas minoritárias, na qual existiria uma ação não sobre os jogadores do jogo, mas sobre as regras do jogo, e enfim, na qual existiria uma intervenção que não é do tipo do assujeitamento interno dos indivíduos, mas uma intervenção de tipo ambiental. (FOUCAULT, 2004b, p. 265).

Deleuze (2004) chamou de sociedade de controle o tipo de sociedade que emerge dessa mutação. São sociedades nas quais as práticas de confinamento tendem a ceder cada vez mais lugar para os controles ao ar livre e os moldes corporais rígidos para as modulações flexíveis do corpo. Nessas sociedades, o regime escolar tende para "formas de controle contínuo, avaliação contínua, e a ação da formação permanente sobre a escola" (DELEUZE, 2004, p. 225). Seria preciso, portanto, considerar na análise duas características que atravessam as práticas sociais de nossos dias: um tipo de intervenção ambiental e uma lógica que é da ordem do controle. Desse modo, procurando responder à questão: sobre quais domínios de objetos atua o investimento pedagógico hoje? Dois domínios possíveis são localizados como hipótese de trabalho: Educação Ambiental e Cultura. Essa hipótese é norteada por certo número de 
preocupações. De que maneira compreender, em nossos dias, a onipresença da esfera ambiental e cultural no cotidiano e, mais particularmente, no escolar? Como explicar que essa onipresença não desperte oposição? Do que procede a força da sua unanimidade? Seria preciso estudar os regimes pedagógicos atuais como práticas transversais que atravessam formas institucionais e domínios conceituais muito variados entre si, tais como educação, meio ambiente e cultura. Considerando as múltiplas dimensões do cotidiano escolar, os fundamentos políticos e pedagógicos da Educação Ambiental e o domínio da cultura, seria preciso cartografar as práticas discursivas nesses três domínios, procurando perceber os processos que Deleuze e Guattari chamaram de reterritorialização e desterritorialização.

Ao contrário de uma metodologia, cartografar ${ }^{2}$ um dispositivo multilinear implica procedimentos que permitam diagnosticar "os pontos de congelamento da capacidade normativa, os limites que urgem a experimentação, a intervenção que desestabiliza e articula fragmentos para a criação de novos modos de existência" (PASSOS; BENEVIDES, 2003, p. 2), evidenciando os modos de perceber, sentir e pensar postos em jogo na relação entre educação, meio ambiente e cultura como configuração específica de domínios do saber e de modalidades de exercício do poder cuja função estratégica se define em relação a problemas considerados cruciais em um momento histórico (FOUCAULT, 1995). O que distingue a cartografia como modo de fazer é que a investigação se faz processualmente, de maneira que "os procedimentos que caracterizam a investigação são conceitualmente da mesma ordem que os procedimentos investigados" (DE CASTRO, 2005, p. 4). Os procedimentos investigados concernem, de um lado e por sua parte, às relações de poder que constituem esses três domínios, estabelecendo, constituindo e modulando as dimensões da existência por meio de práticas sociais que os atualizam enquanto tais, deste ou daquele modo, na experiência cotidiana; concernem, portanto, à relação entre o dispositivo educacional-ambiental-cultural que o currículo põe em funcionamento ao engendrar uma alquimia por meio da qual são produzidos modos de subjetivação cada vez menos disponíveis à variação e mais afeitos à variedade (diversidade). Por outro lado, concernem aos modos pelos quais a/na experiência cotidiana inesgotável e inacabada, outra alquimia ${ }^{3}$ é inventada, gerando fissuras nos estados de dominação, constituindo-se 
como uma prática menor - não afeita às representações e ideações atuantes no currículo - e que remetem a "uma estética intrínseca dos modos de existência como última dimensão dos dispositivos" liberada dos modelos moralizantes (DELEUZE, 1990, s/p). Essa alquimia exprime-se em outra distribuição de linhas, que Deleuze chamou de fugas, e que contrariam a configuração que o dispositivo engendra, desarticulando-o. A alquimia aqui se coloca como transmutação das ideações curriculares em que a pretensão ao conhecimento afirma-se não como problema cognitivo circunscrito por suas condições de possibilidade, mas como problematização política "da legitimidade atribuída aos discursos que entram em relação de conhecimento, e, em particular, às relações de ordem que se decide estatuir entre esses discursos, que certamente não são inatas, como tampouco o são seus pólos de enunciação" (DE CASTRO, 2002).

O evidente caráter experimental implicado na cartografia tal qual a propomos articula algumas noções e alguns conceitos que merecem maior explicitação, particularmente aqueles que dizem respeito a uma compreensão da cultura e do cotidiano. É desnecessário elencar o variado conjunto de perspectivas que compõem os estudos em educação, cotidiano e cultura, que, de forma alguma, desconhecemos, restando apenas delinear a singularidade daquela que orienta a abordagem apresentada ${ }^{4}$. A tessitura teórico-metodológica que delineamos vale-se dos estudos foucaultianos a propósito do cotidiano escolar, numa composição singular com as contribuições de uma abordagem deleuzeana, bem como do experimento etnológico proposto por Viveiros de Castro (2005) visto a apropriação da etnologia, como ferramenta de pesquisa, fazer-se já usual no âmbito da pesquisa em educação naquela vertente que privilegia o campo dos estudos culturais.

Posto isso, ao considerarmos o caráter singular do acontecimento - como contra-efetuação de uma relação de forças em relação à qual o próprio acontecimento não é indiferente, visto afirmar o jogo das forças na história (FOUCAULT, 1999, p. 145-172) -, abre-se a possibilidade de pensar aquilo que o "evento" encobre ou escamoteia ${ }^{5}$. Nessa perspectiva interessa a expressão singular das práticas, isto é, a variação como qualidade do acontecimento, visto o acontecimento ser precisamente "tudo que não é evidente" (VEYNE, 1971, p. 18). Sem nos alongarmos exaustivamente em matéria já abordada de maneira minuciosa 
por Hélio Rebello Cardoso Jr., é a imantação entre as práticas e sua dimensão acontecimental que trazem como exigência a atenção a determinadas configurações históricas e, portanto, aos regimes de visibilidade e dizibilidade, mas também àquilo que as percorre subterraneamente, onde se reinstala a estranheza do mundo, "instigando a interrogação e, com ela, o senso filosófico" (CARDOSO JR., 2005, p. 5). O caráter do senso filosófico é aqui alcançado pela colusão entre prática e acontecimento, operada por Deleuze e comentada por Foucault, pois, ao mesmo tempo em que o acontecimento se efetua num estado de coisas ou configuração histórica que o torna possível, é preciso, e efetivamente para Deleuze é o que importa, que se saiba operar nele uma contra-efetuação, uma reversão da posição em relação à ordem causal expressa nos estados de coisa.

A problematização afirma o pensar na sua implicação necessária com a dimensão da criação na ciência e na técnica, na filosofia, na arte e na conduta humana irredutível à reflexão sobre determinada questão ou ao reconhecimento do estado de coisas que ela exprime. Aponta na direção de uma alteração do estado cotidiano de existência, cuja operatoriedade Michel de Certeau (1998) explicita ao elencar as três lógicas que subjazem à cozinha: 1) a lógica das qualidades sensíveis, que diz da escolha dos elementos considerados comestíveis; 2) a lógica das formas, que diz das misturas permitidas e dos modos de preparação reconhecidos; e, finalmente, 3 ) a lógica das proposições, que diz das boas maneiras à mesa e do calendário das proibições. Funcionando a partir de grande número de exclusões, de um número limitado de autorizações e de um círculo de compatibilidades, Certeau explicita, por meio da cozinha, o próprio esquema sensível da moldura cultural, que está sempre "radicada em determinado tipo de experiência concreta do mundo (...) que, no nosso caso, é o da produção, da imposição de uma forma” (DE CASTRO, 2005) ou re-forma, em que as culturas emergem como diferentes soluções interiores ao esquematismo, que permanece inalterado ${ }^{6}$.

Do modo como a tomamos, a cozinha de Certeau não é redutível, portanto, a uma dimensão da cultura que se encontra no cotidiano, mas é a própria produção cotidiana da cultura, o acontecimento cultural, na sua inscrição nos corpos e estados de coisa, configurando o cotidiano "no seu aspecto fastidioso, penoso e sórdido (o amorfo, o estagnante), e o cotidiano inesgotável, irrecusável e sempre inacabado, 
sempre escapando às formas" (BLANCHOT, 2007, p. 237) ou aos dispositivos burocráticos e governamentais cuja afirmatividade se exprime na invenção de microrresistências. Nesse sentido, 'cultura' não tem existência independente de sua atualização nas relações sociais e do movimento dos saberes e poderes que as configuram como práticas.

Apreender o que não é evidente, isto é, o acontecimento no evento, é apreender a contra-efetuação enquanto ela se faz no encontro com aquilo que ainda não está determinado. Nesse sentido, a pesquisa em educação, meio ambiente e cultura apresenta-se como experimento (que de fato são), desarranjando o funcionamento do dispositivo que opera de maneira a organizar tudo o que se passa - os modos como agimos, sentimos, percebemos e pensamos as questões, problemas e práticas cotidianas - para que nada nos aconteça, isto é, para que permaneçamos idênticos ao conjunto de disposições modelares.

\section{Algumas considerações}

A partir dos anos 1990, os estudos relacionados com história da educação conheceram uma renovação de seus pressupostos. Essa renovação, como apontaram Warde \& Carvalho (2001, p. 87), caracterizou-se pela ênfase concedida à materialidade das práticas pedagógicas, dos objetos e de seus usos, reconfigurando não apenas a história da pedagogia como a própria história da instituição escolar, agora concebidas como produtos da interação entre dispositivos de normalização pedagógica e as práticas dos agentes neles relacionados. Nomeados "pedagogia pós-crítica", esses estudos vieram preencher algumas lacunas deixadas pelas análises das pedagogias críticas ou "freirianas". Essa abordagem apoia-se, sobretudo, em estudos que trabalham com o pensamento de Foucault e Deleuze, lançando mão de outras categorias para pensar e fazer a pesquisa em educação no Brasil, cuja experimentação deu-se, como mostrou (PARAÍSO, 2004), em três movimentos distintos: um buscando sintetizar e divulgar as potencialidades analíticas da crítica pós-estruturalista para pensar questões da educação no Brasil (SILVA, 1994; 1995; LOURO, 1994; FISCHER, 1994 E VEIGA-NETO, 1994; 1995; 1996); Outro discutindo 
diferentes objetos no campo educacional: o construtivismo pedagógico (CORAZZA,1994), o conhecimento didático (OGIBA, 1994), as metodologias participativas de pesquisas (COSTA, 1995), as reformas educacionais (MARZOLA, 1995), a educação ambiental (REIGOTA, 1999; 2006; GRÜN, 1995), a produção do feminino e do masculino nas práticas escolares (LOURO, 1995). Por último, trabalhando questões de procedimentos de pesquisa e modos de pesquisar em educação (COSTA, 1996; COSTA \& GRÜN, 1996; CORAZZA, 1996; BEATRIZ FISCHER, 1996; ROSA FISCHER, 1996; 1998; LOURO, 1996; OGIBA ET AL., 1996 E VEIGA-NETO, 1996).

Do mesmo modo, interessa-nos considerar, dentro do vasto campo do Meio Ambiente, o domínio da Educação Ambiental. Para compreender como o ambiente vai habitar a educação, tornando-se objeto de reflexão distinto, o trabalho de Grün (2006) é elucidativo ao mostrar a trajetória pela qual emerge como "assunto oficial", no ano de 1972, durante a "Primeira Conferência das Nações Unidas sobre o Meio Ambiente" de Estocolmo, até sua consolidação definitiva, na Eco-92. Reigota (1994; 2006) fornece igualmente informações precisas para compreender o processo de legitimação política, social e científica da Educação Ambiental no Brasil. Por sua vez, Sato e Santos (2003), ao sistematizarem conceitualmente o tema, propuseram um mapeamento segundo o qual as investigações relacionadas com Educação Ambiental evidenciam quatro eixos principais: o positivismo, que tem por paradigma o "objetivismo"; o construtivismo, que admite uma realidade multifacetada e uma ontologia relativista; o socioconstrutivismo, ligado à Teoria Crítica, portanto, interessado em ações constitutivas com valores emancipativos; por fim, mais recentemente, o eixo pós-estruturalista, que, no entanto, encontra-se ainda imprecisamente formulado. Trata-se de quatro vertentes que, assumindo a Educação Ambiental como processo educativo, estão preocupadas com a questão: qual é a base pedagógica capaz de orientar as ações no campo da Educação Ambiental?

Considerando a analítica genealógica adotada nessa abordagem, seria preciso deslocar os acentos e, em vez de perguntar sobre o conteúdo pedagógico da Educação Ambiental, perceber como o próprio termo porta, como mostraram Godoy (2008a) e Hardt (2000), um propósito de totalização. Ao perceber como os valores veiculados pela Educação Ambiental comportam uma medida comum para interesses particulares e variados, essa abordagem possibilita a problematização da Educação 
Ambiental como política de governo. Assim, tendo em vista a noção de alquimia, proposta por Popekewitz, apresentada no início deste artigo, e as considerações aqui elencadas, é necessário tomar a articulação entre um tipo de intervenção ambiental e uma lógica que é da ordem do controle como o horizonte de uma racionalidade estratégica que põe em primeiro plano a regulação "da maneira como o mundo se apresenta imediatamente a nós no curso de nossa existência". Tratar-se-ia, sobretudo, de uma intervenção nas tonalidades, no que Uexkull (s/d, p. 10) chamou "teor" prático ou qualidades intensivas por meio das quais se produzem o mundo de percepção e o mundo de ação; intervenção que supõe necessariamente a modificação incessante do meio ${ }^{7}$, ao mesmo tempo em que implica a modulação das tendências e disposições através das quais a regulação se efetiva e a partir das quais se produz uma norma de conduta social.

A articulação entre intervenção ambiental e controle implica não só uma mudança dos padrões cognitivos, mas uma transformação das práticas (as formas de visibilidade, as maneiras distintas de pensamento e os procedimentos de produção da verdade, os modos específicos de ação, intervenção e direção, e os modos de formação de sujeitos) e, sobretudo, uma transformação do conjunto dos procedimentos e das instituições, redimensionando a função alquímica, isto é, redimensionando a inscrição pedagógica do cidadão nos indivíduos, tendo em vista a formação do cidadão planetário, aquele capaz de atuar como agente de mudanças em relação às questões ambientais (FREITAS; OLIVEIRA, 2004).

Esse conjunto de inversões alquímicas exprime-se nos processos de ambientalização curricular, ambientalização institucional, ambientalização da educação e ambientalização da sociedade ${ }^{8}$, através do qual são reconfigurados o estatuto profissional, a pesquisa e o ensino, colocando em jogo uma racionalidade ambiental ${ }^{9}$ que articularia práticas sociais, interesses e domínios distintos, legitimando o próprio espaço enunciativo que a torna possível, fazendo com que ele entre em ressonância com as modulações do processo de subjetivação. Desse modo, a perspectiva ambiental, antes restrita à transformação temporal da cognição (KASTRUP, 2000, p. 379), passa a presidir a própria produção do espaço enunciativo, isto é, o conjunto das práticas e das ações ensejadas pelos indivíduos em qualquer tempo e lugar.

É preciso considerar ainda que esses processos são alavancados pelo dispositivo de controle da democracia participativa, que, como 
afirma Tótora (2006, p. 243), incessantemente integra as minorias às maiorias, contendo os fluxos vivos que escapam ou "que os procedimentos majoritários de representação não conseguem conter”, reconhecendo direitos e distribuindo deveres sob a forma de responsabilidade social. Todavia, trata-se menos de moldar indivíduos do que de modular as subjetividades, controlando as disposições, acentuando tendências, operando no "amplo espaço entre eu e mim mesmo" (CARDOSO JR., 2002, p. 195), de maneira que não haveria um dispositivo que pudesse ser determinado como central, mas fluxos de toda sorte (de opinião, de consumo, de sexualidade, de informação, de afetos) reunidos desta ou daquela maneira pelo controle em função de uma axiomática, que é o próprio capitalismo e que, no entanto, não para de multiplicar axiomáticas "para os jovens, para os velhos, para as mulheres" (DELEUZE; GUATTARI, 1997, p. 163), mas também para os animais, as plantas e a Terra.

Em relação ao campo cultural, as dificuldades não são menores. A noção de cultura é inerente à reflexão das ciências humanas. É necessária para a construção de uma unidade integrativa em larga escala social para além dos termos biológicos. Seu campo discursivo é, portanto, quase inesgotável. O trabalho de Cuche (1999) fornece uma boa introdução ao problema. Entretanto, como assinalou Ivison (2002, p. 35), dois modos são recorrentes ao conceber a cultura. Um refere-se à cultura como "corpo totalizador de comportamentos", como "conjunto individualizável" de crenças e práticas duradouras, tradicionais e estruturais, que portam expectativas enraizadas, existência estável e territorializada. Outro, mais recente, é a cultura como tecido permeável e contingente, em cujo interior agem grupos e indivíduos. Trata-se de uma realidade negociável formada por materiais substituíveis, constituindo "um nexo de relações e transações engajando ativamente sujeitos" (IVISON, 2002, p. 36).

Também aqui é adotada outra perspectiva que permite escapar a esse dualismo. Então, em vez de perguntar o que é, é preciso permanecer no como da cultura. Hindess e Helliwell (1999, p. 2) tomaram cultura, sociedade, civilização como concepções que denotam unidades ao mesmo tempo ideacionais e sistemáticas, "cumprem o duplo papel de inscrever identidades ideais no interior de uma população, bem como diferenças entre uma população e outra”. Geertz (1989, p. 56), por sua vez, afirmou a cultura "como um conjunto de mecanismos de controle - planos, receitas, 
regras, instruções (...) para governar o comportamento”. Nesse sentido, a cultura pode ser pensada além de sua função de simples mediadora e depositária dos valores e escolhas de sujeitos autônomos de um campo cultural dado. É também um "espaço enunciativo" no interior do qual o indivíduo se move entre modos de subjetivação e possibilidades de individuação. A cultura, nesse sentido, é performativa. Sua linguagem é constitutiva com a política e suporta a episteme do governo (AVELINO, 2008, p. 119). Assim, o termo "tecnologias intelectuais", de Rose e Miller (2008, p. 57), serve para pensar a análise cultural, elucidando "não apenas o sistema de pensamento (...), mas também o sistema de ação que torna o governo efetivo".

É preciso evitar, entretanto, tomar o caráter performativo da cultura como a liberdade do indivíduo frente aos conceitos em relação aos quais ele ganharia autonomia. Como argumentou Sahlins (1999, p. 11), o campo cultural é um domínio que sempre envolve certo tipo de servidão, na medida em que "não temos, por exemplo, a liberdade de sairmos por aí nomeando as coisas 'simplesmente pelo modo que elas são', como fez Adão, 'parecia-se com um leão e rugia como um leão, portanto o chamei de leão". A performance depende, em grande medida, das possibilidades dadas de significação, do contrário, diz Sahlins, elas seriam ininteligíveis e incomunicáveis. O problema é que o aspecto performativo é quase sempre ignorado, fazendo a análise recair prioritariamente sobre as formas culturais. Daí a importância da afirmação de Sahlins segundo a qual as relações entre as formas culturais e os atos apropriados são perfeitamente reversíveis. Se "a forma cultural (ou morfologia social) pode ser produzida ao avesso: a ação criando a relação adequada, performativamente, exatamente como em certos famosos atos de discurso: 'Eu vos declaro marido e mulher"' (SAHLINS, 1999, p. 12), torna-se igualmente necessário perceber quais tipos de práticas e de ações são capazes de precipitar formas culturais globais.

Retomando a formulação de Sahlins, o problema que se coloca é o de saber, a partir da perspectiva global de uma sociedade, de que maneira finalidades subjetivas locais tornam-se meios importantes para a constituição de determinada ordem política, econômica e moral. Não existe prática social que não possa ser examinada de um ponto de vista cultural, uma vez que os valores simbólicos da cultura são constitutivos da ação humana (cf. MINC/PNC); todavia, como notaram alguns autores do 
campo dos Estudos Culturais (JOHNSON; ESCOSTEGUY; SHULMAN, 2006), é menos evidente o modo como as formas culturais funcionam subjetivamente, não obstante a natureza histórica da vida subjetiva das relações sociais. Nessa direção, o trabalho de David Garland (2004) é bastante significativo. Considerando equivocado focalizar a atenção exclusivamente nos processos de transformação e representação política, visto dependerem, em larga medida, de hábitos sociais e sensibilidades culturais preexistentes, Garland (2004, p. 244), ressaltando a importância para o processo político das percepções e das emoções relativas à experiência cultural coletiva, afirma que as sensibilidades culturais "constituem, de fato, as condições pré-políticas que tornam hoje possível (em sentido técnico) e desejável (aos olhos de amplos setores eleitorais) escolhas extra-políticas", sustentando que as "novas políticas de controle são socialmente e culturalmente condicionadas; e que seu conteúdo, o momento histórico em que são afirmadas e sua popularidade não podem ser compreendidos, a não ser colocando-os em relação com as transformações da prática social e das sensibilidades culturais" (GARLAND, 2004, p. 245) passíveis de uso e manipulação pelos policy makers e pelos opinion makers na direção de objetivos determinados. Tais práticas e sensibilidades põem em jogo tanto certa receptividade das formas de ver quanto certa espontaneidade do conjunto de enunciados que, sendo inseparáveis de um regime de práticas pedagógicas, atualizam os modos de engajamento e vinculação dos indivíduos ao modelo de aprendizagem e motivação que distingue dada formação.

Desse modo, políticas de Estado não prescindem dos sentidos culturais da sociedade civil que engendram a criação lenta de controles sociais "espontâneos", em outras palavras, a criação de "práticas habituais e automáticas, fruto do aprendizado, consistindo na vigilância recíproca, na reprovação, na punição e na deploração praticados habitualmente pelos membros de uma comunidade" (GARLAND, 2004, p. 270). Em suma, não prescindem de uma cultura do controle previamente esboçada. O que está em jogo, como afirmou Lazzarato (2005), é a captura das modulações qualitativas do cidadão-trabalhador, suas escolhas, seus comportamentos, suas decisões, suas ações; mas também a produção, naqueles que não as possuem, das condições de autonomia individual que lhes permitirão praticar sobre si mesmos as técnicas por meio das quais poderão escolher, comportar-se, decidir e agir. A necessidade de formar e aperfeiçoar, de 
fazer e manejar inversões na educação escolar, na saúde, na mobilidade, nos afetos, nas relações de todo tipo diz respeito não somente à correção ou à regulação de comportamentos que seriam considerados danosos (prescrição), mas à produção (incitamento) de comportamentos que não cessem de responder ao problema da inovação, em todas as dimensões da existência individual e coletiva. Faz-se necessário, portanto, mobilizar toda uma série de dispositivos que permitam atuar sobre o nível e o conteúdo do capital humano (capital cultural), isto é, que permitam intervir no conjunto de condições da vida, buscando a constituição de subjetividades afeitas às solicitações de escolhas, decisões e ações, dentro de um universo de possíveis que é inseparável do espaço enunciativo ou de uma moldura cultural que as organiza por proposição, sugestão ou imposição.

Indicamos neste breve artigo algumas articulações e funcionamentos de um dispositivo educacional-ambiental-cultural em que a reivindicação e o reconhecimento de direitos, os quais definem o dispositivo democrático participativo, passam a operar exclusivamente na dimensão da solução criativa de problemas dados. Contrariar a configuração engendrada pelo dispositivo implica a afirmação do direito a inventar e a formular os próprios problemas, por meio de práticas singulares que minam a ordem e a hierarquia dos discursos legitimados, liberando a diferença do sistema de igualdade que a aprisiona em que qualquer um é igual a qualquer um, segundo um esquema de equivalências jurídicas e morais. Ao contrário de alquimias pedagógicas, talvez uma pedagogia alquímica...

\section{Referências}

ALVES, N. Cultura e cotidiano escolar. Anais da XXV Reunião Anual da ANPEd, Caxambu, 29/9 a 2/10, 2002. Disponível em:

< http://www.scielo.br/pdf/rbedu/n23/n23a04.pdf>. Acessado em 22 nov. 2008.

AVELINO, N. Anarquismos e governamentalidade. 400f. Tese (Doutorado em Ciências Sociais - Política), Pontifícia Universidade Católica de São Paulo, 2008.

BLANCHOT, M. A fala cotidiana. In: BLANCHOT, M. A conversa infinita 2: a experiência limite. São Paulo: Escuta, 2007.

BOEIRA, S. L. Saber Ambiental: resenha. Ambiente \& Sociedade, Campinas, Ano V, n. 10, $1^{\circ}$ semestre, p. 143-146, 2002. Disponível em:

$<$ http://www.scielo.br/scielo.php?pid=S1414-753X2002000100010\&script=sci_arttext $>$. Acessado em 9 jun. 2008.

CARDOSO JR., H. R. Foucault e Deleuze em co-participação no plano conceitual. In: 
RAGO, M.; ORLANDI, L. B. L.; VEIGA-NETTO, A. (Orgs.). Imagens de Foucault e Deleuze: ressonâncias nietzscheanas. Rio de Janeiro: DP\&A, 2002.

CARDOSO JR., H. R. Acontecimento e história: pensamento de Deleuze e problemas epistemológicos contemporâneos das ciências humanas. Trans/Form/Ação, São Paulo, v. 28, n. 2, p. 105-116, 2005. Disponível em:

<http://www.scielo.br/pdf/trans/v28n2/29417.pdf>. Acessado em 22 nov. 2008.

CERTEAU, M. A invenção do cotidiano: 1. Artes de fazer. Petrópolis: Vozes,1994.

CERTEAU, M. A invenção do cotidiano: 2. Morar, cozinhar. Petrópolis: Vozes,1998.

CORAZZA, S. M. O Construtivismo pedagógico como significado transcendental do currículo. In: REUNIÃO ANUAL DA ANPED, Programa e resumos. Associação Nacional de Pós-Graduação e Pesquisa em Educação, 17, 1994.

CORAZZA, S. M. Labirinto da pesquisa diante dos ferrolhos. In: COSTA, M. (Org.) Caminhos investigativos: novos olhares da pesquisa em educação. Porto Alegre: Mediação, 1996. p. 105-131.

CORR A, G. Educação, comunicação, anarquia. Procedências da sociedade de contrôle no Brasil. São Paulo: Cortez, 2006.

COSTA, M.; GRUN, M. A aventura de retomar a conversação: hermenêutica e pesquisa social. In: COSTA, M. (Org.) Caminhos investigativos: novos olhares da pesquisa em educação. Porto Alegre: Mediação, 1996. p. 85-104.

COSTA, M. Elementos para uma crítica das metodologias participativas de pesquisa. In: VEIGA-NETO, A. (Org.) Crítica pós-estruturalista e educação. Porto Alegre: Sulina, 1995. p. 109-158.

COSTA, M. Caminhos investigativos: novos olhares da pesquisa em educação. Porto Alegre: Mediação, 1996.

CRUIKSAHNK, B. The will to Empower: democratic citizens and other subjects. New York: Cornell University, 1999.

CUCHE, D. A noção de cultura nas ciências sociais. Trad. Viviane Ribeiro. Bauru: Edusc, 1999.

DE CASTRO, E. V. O nativo relativo. Mana, v. 8, n. 1, Rio de Janeiro, abril, 2002.

DE CASTRO, E. V. Eduardo Viveiros de Castro: a filosofia canibal. Folha de S.Paulo, 21 ago, 2005. Caderno Mais!

DE GIORGI, A. Il governo dell'eccedenza. Postfordismo e controllo della moltitudine. Verona: Ombre Corte, 2002.

DEAN, M. Governmentality: power and rule in modern society. Londres: Sage Publ, 1999. DELEUZE, G. O que é um dispositivo?. Trad. Wanderson F. do Nasciemento. EscolaNômade.org, 1990. Disponível em: <http://escolanomade.org/tiki/tikiread_article.php?articleId=47>. Acessado em 22 nov. 2008.

DELEUZE, G. Mil Platôs - capitalismo e esquizofrenia, vol. 5. Trad. Peter Pál Pelbart e Janice Caiafa. São Paulo: Editora 34, 1997.

DELEUZE, G. O que é a filosofia? Rio de Janeiro: Ed. 34, 2000.

DELEUZE, G. Conversações, 1972-1990. Trad. Peter Pál Pelbart. São Paulo: Ed. 34, 2004.

DURAN, M. C. G. Maneiras de pensar o cotidiano com Michel de Certeau. Diálogo Educacional, Curitiba, v. 7, n. 22, p. 115-128, set./dez, 2007. Disponível em:

<http://www2.pucpr.br/reol/index.php/DIALOGO?dd1=1577\&dd99=pdf $>$. Acessado em 22 nov. 2008. 
FISCHER, B. Foucault e histórias de vida: aproximações e que tais. In: REUNIÃO ANUAL DA ANPED. Programa e resumos. Associação Nacional de Pós-Graduação e Pesquisa em Educação, 24, 1996.

FISCHER, R. Análise do discurso: para além das palavras e das coisas. In: REUNIÃO ANUAL DA ANPED. Programa e resumos. Associação Nacional de Pós-Graduação e Pesquisa em Educação, 17, 1994

FISCHER, R. A Paixão de 'trabalhar com' Foucault. In: REUNIÃO ANUAL DA ANPED. Programa e resumos. Associação Nacional de Pós-Graduação e Pesquisa em Educação, 19, 1996.

FISCHER, R. O Estatuto pedagógico da mídia: questões de análise. In: REUNIÃO ANUAL DA ANPED. Programa e resumos. Associação Nacional de Pós-Graduação e Pesquisa em Educação, 21, 1998.

FOUCAULT, M. Nietzsche, Frend e Marx: Theatrum Philosoficum. Porto: Anagrama,1980.

FOUCAULT, M. Dits et écrits, vol. II. Paris: Gallimard, 1994.

FOUCAULT, M. Nietzsche, a genealogia e a história. In: FOUCAULT, M. Microfísica do poder. 14 ed. Trad. Roberto Machado. Rio de Janeiro: Graal, 1999.

FOUCAULT, M. Vigiar e punir. Nascimento da prisão. 22 ed. Trad. Raquel Ramalhete. Petrópolis: Vozes, 2000.

FOUCAULT, M. $A$ verdade e as formas jurídicas. 3 ed. Trad. Roberto Machado e Eduardo Morais. Rio de Janeiro: Nau editora, 2002.

FOUCAULT, M. Sécurité, territoire, population. Cours au Collège de France, 1977-1978. Paris: Gallimard/Seuil, 2004a.

FOUCAULT, M. Naissance de la biopolitique. Cours au Collège de France, 1978-1979. Paris: Gallimard/Seuil, 2004b.

FREITAS, D.; OLIVEIRA, H. T. Uma reflexão sobre o valor do trabalho desenvolvido pela REDE ACES no período de sua implementação. In: GELI, A. M.; JUNYENT, M.; SÁNCHEZ, S. (Orgs.). Ambientalización Curricular de los Estudios Superiores, v. 4 - Acciones de Intervención y labance final del proyecto de Amientalización Curricular de los Estudios Superiores. Girona: UdG, 2004.

GALLO, S. Deleure \& a Educação. Belo Horizonte: Autêntica, 2003.

GANDIN, L. A.; PARASKEVA, J. M.; HYPOLITO, A. M. Mapeando a [complexa] produção teórica educacional - Entrevista com Tomaz Tadeu da Silva. Currículo sem Fronteiras, v. 2, n. 1, p. 5-14, Jan/Jun, 2002. Disponível em:

$<$ www.curriculosemfronteiras.org/vol2iss1articles/tomaz.pdf>. Acessado em 22 nov. 2008.

GARLAND, D. La Cultura del Controllo. Crimine e ordine sociale nel mondo contemporaneo. Trad. Adolfo Ceretti e Francesca Gibellini. Milão: il Saggiatore, 2004.

GEERTZ, C. A interpretação das culturas. [s/t]. Rio de Janeiro: LTC, 1989.

GODOY, A. A menor das ecologias. São Paulo: Edusp, 2008a.

GODOY, A. Educação, meio ambiente e subjetividade na sociedade de controle: por uma ética dos afectos. Revista Interacções, 2008b. (artigo aceito para publicação)

GOUVEAA, M. C. S. de; JINZENJI, M. Y. Escolarizar para moralizar: discursos sobre a educabilidade da criança pobre (1820-1850). Revista Brasileira de Educação, v. 11, n 31, 2006. Disponível em: 
<http:/ /www.scielo.br/scielo.php?pid=S1413-4782006000100009\&script=sci_arttext $>$ Acessado em 22 nov. 2008.

GRÜN, M. A produção discursiva sobre educação ambiental: terrorismo, arcaísmo e transcendentalismo. In: VEIGA-NETO, A. (Org.) Crítica pós-estruturalista e educação. Porto Alegre: Sulina, 1995. p. 159-184.

GRÜN, M. Ética e Educaşão Ambiental. A conexão necessária. 10 ed. Campinas: Papirus, 2006.

HARDT, M. “A sociedade mundial de controle”. In: ALLIEZ, É. (org.). Gilles Deleuze: uma vida filosófica. Tradução Ana L. de Oliveira. São Paulo: Ed. 34.

HINDESS, B.; HELLIWELL, C. 'Culture', 'society' and the figure of man. History of the Human Sciences, v. 12, n. 4, p. 1-20, 1999.

IVISON, D. Postcolonial Liberalism. Cambridge: Cambridge University Press, 2002.

JOHNSON, R.; ESCOSTEGUY, A. C.; SCHULMAN, N. O que é, afinal, Estudos Culturais? 3 ed. Org. e trad. Tomaz T. da Silva. Belo Horizonte: Autêntica, 2006.

KASTRUP, V. O devir-criança e a cognição contemporânea. Psicologia: Reflexão e Crítica, Porto Alegre, v. 13, n. 3, p. 373-382, 2000. Disponível em:

$<$ http://www.scielo.br/scielo.php?pid=S0102-79722000000300006\&script=sci_arttext $>$. Acessado em 9 jun. 2008.

LARROSA, J. Notas sobre a experiência e o saber de experiência. I Seminário Internacional de Educação de Campinas, 2001. Disponível em:

$<$ http://www.campinas.sp.gov.br/smenet/seminario/seminario_pronto_jorgelarrosa.ht m>. Acessado em 22 nov. 2008.

LAZZARATO, M. Biopolitique/Bioéconomie. Multitudes, n. 22, outono, 2005. Disponível em: <http://multitudes.samizdat.net/Biopolitique-Bioeconomie> Acessado em 9 jun. 2008.

LOURO, G. L. Os Estudos de gênero e a história da educação: desafios de uma proposta teórica. In: REUNIÃO ANUAL DA ANPED. Programa e resumos. Associação Nacional de Pós-Graduação e Pesquisa em Educação, 17, 1994.

LOURO, G. L. Educação e gênero: a escola e a produção do feminino e do masculino. In: SILVA, L. H.; AZEVEDO, J. C. (Orgs.) Reestruturação curricular. Petrópolis: Vozes, 1995. p. 172-182.

LOURO, G. L. Educação e gênero. In: REUNIÃO ANUAL DA ANPED. Programa e resumos. Associação Nacional de Pós-Graduação e Pesquisa em Educação, 19, 1996.

MARZOLA, N. Para uma teoria da mudança educacional. In: VEIGA-NETO, A. (Org.) Crítica pós-estruturalista e educação. Porto Alegre: Sulina, 1995. p.185-211.

MINISTÉRIO DA EDUCAÇÃO E CULTURA. Plano Nacional de Cultura. Disponível em: <http://www.cultura.gov.br/site/pnc/introducao/>. Acessado em 22 nov. 2008.

MINISTÉRIO DO MEIO AMBIENTE. Educação Ambiental. Disponível em: $<$ http:/ / www.mma.gov.br/index.php?ido=conteudo.monta\&idEstrutura $=20>$. Acessado em 22 nov. 2008.

MINISTÉRIO DA EDUCAÇÃO E CULTURA. Mapeamento da Educação em Instituições Brasileiras de Educação Superior: elementos para políticas públicas. Série Documentos Técnicos, 1. Disponível em:

<http://74.125.47.132/search?q=cache:AQAaKQ5C_XIJ:portal.mec.gov.br/secad/arq uivos/pdf/educacaoambiental/dt12.pdf + Programa+de+Ambientalizaci $\% \mathrm{C} 3 \% \mathrm{~B} 3 \mathrm{n}+\mathrm{C}$ 
urricular + de + los + Estudios + Superiores $\& c d=19 \& \mathrm{hl}=\mathrm{pt}-\mathrm{BR} \& \mathrm{ct}=\mathrm{clnk} \& \mathrm{gl}=\mathrm{br}>$. Acessado em 9 jun. 2008.

NAÇÕES UNIDAS. Declaração do Milénio, Cimeira do Milénio, 6-8 de setembro de 2000, Nova Iorque. Disponível em:

$<$ http://www.ence.ibge.gov.br/pos_graduacao/mestrado/Declaracao_do_milenio.pdf >. Acessado em 22 nov. 2008.

OGIBA, S. M. A Produção do conhecimento sobre a didática e o pós-estruturalismo: potencialidades analíticas. In: REUNIÃO ANUAL DA ANPED. Programa e resumos. Associação Nacional de Pós-Graduação e Pesquisa em Educação, 17, 1994.

OGIBA, S. M. et al. Limites da teorização educacional moderna: implicações no campo da docência. In: REUNIÃO ANUAL DA ANPED. Programa e resumos. Associação Nacional de Pós-Graduação e Pesquisa em Educação, 19, 1996.

ORLANDI, L. B. L. O gato entre Alice e Foucault. In: RAGO, M.; VEIGA-NETO, A. Figuras de Foucault. Belo Horizonte: Autêntica, 2006. p. 147-154. Disponível em: $<$ http://www.fe.unicamp.br/dis/transversal/rizomas/O_gato_entre_Alice_e_Foucault. doc $>$. Acessado em 22 nov. 2008.

PARAÍSO, M. A. Pesquisas pós-críticas em educação no Brasil: esboço de um mapa. Cadernos de Pesquisa, v. 34, n. 122, maio/ago, p.283-303, 2004.

PASSOS, E.; BENEVIDES, R. Complexidade, transdisciplinaridade e produção de subjetividade. In: FONSECA, T. M. G.; KIRST, P. G. Cartografias e Devires: a construção do presente. Porto Alegre: Editora da UFRGS, 2003.

POPKEWITZ, T. S. Reforma educacional, uma política sociológica. Poder e conhecimento em educação. Trad. Beatriz A. Neves. Porto Alegre: Artes Médicas, 1997.

POPKEWITZ, T. S. The Denial of Change in Educational Change: Systems of Ideas in the Construction of National Policy and Evaluation. Educational Researcher, v. 29, n. 1, 2000, p. 17-29.

POPKEWITZ, T. S. How the Alchemy Makes Inquiry, Evidence, and Exclusion. Journal of Teacher Education, v. 53, n. 3, p. 262-267, 2002.

POPKEWITZ, T. S. The Alchemy of the Mathematics Curriculum: Inscriptions and the Fabrication of the Child. American Educational Research Journal, v. 41, n. 1, p. 3-34, 2004.

PROCACCI, G. Gouverner la misère. La question sociale en France (1789-1848). Paris: Éditions du Seuil, 1993.

REIGOTA, M. A floresta e a escola: por uma educação ambiental pós-moderna. São Paulo: Cortez, 1999.

REIGOTA, M. A educação ambiental frente ao esfacelamento da cidadania no governo Lula (2002-2006), 2006. Disponível em:

$<$ http://www.portaldomeioambiente.org.br/JMA-txt_importante_anpepp_16.08.06.pdf > . Acessado em 22 nov. 2008.

ROSE, N.; MILLER, P. Governing the Present. Administering Economic, Social and Personal Life. Cambridge: Polity Press, 2008.

SATO, M.; SANTOS, J. E. Tendências nas pesquisas em educação ambiental. In: NOAL, F.; BARCELOS, V. (Orgs.) Educação ambiental e cidadania: cenários brasileiros. Santa Cruz do Sul: Edunisc, 2003. p. 253-283.

SAHLINS, M. Ilhas de História. Trad. Barbara Sette. Rio de Janeiro: Zahar, 1999.

THOMPSON, E. P. Costumes em comum. Estudos sobre a cultura popular tradicional. 
Trad. Rosaura Eichemberg. São Paulo: Cia. das Letras, 1998.

SILVA, T. T. O Adeus às metanarrativas educacionais. In: SILVA, T. T. (Org.) O sujeito da educação: estudos foucaultianos. Petrópolis: Vozes, 1994. p. 247-258.

SILVA, T. T. Currículo e identidades sociais: outros olhares. In: REUNIÃO ANUAL DA ANPED. Programa e resumos. Associação Nacional de Pós-Graduação e Pesquisa em Educação, 18, 1995.

TÓTORA, S. Democracia e sociedade de controle. Verve, São Paulo, n. 10, p. 237-260, 2006.

UEXKULL, J. V. Dos animais e dos homens. Trad. Alberto Candeias e Aníbal G. Pereira. Lisboa: Livros do Brasil, s/d.

VEIGA-NETO, A. Foucault e educação: outros estudos foucaultianos. In: SILVA, T. T. (Org.) O sujeito da educação: estudos foucaultianos. Petrópolis: Vozes, 1994. p. 225-246.

VEIGA-NETO, A. Michel Foucault e educação: há algo de novo sob o sol? In: VEIGA-

NETO, A. (Org.) Crítica pós-estruturalista e educação. Porto Alegre: Sulina, 1995. p. 9-56

VEIGA-NETO, A. Foucault e educação. In: REUNIÃO ANUAL DA ANPED. Programa e resumos. Associação Nacional de Pós-Graduação e Pesquisa em Educação, 19, 1996.

VEYNE, P. Comment on Écrit l'Histoire. Paris: Seuil, 1971.

WARDE, M. J.; CARVALHO, M. M. C. de. Politics and Culture in the Making of History of Education in Brazil. In: POPKEWITZ, T. S.; FRANKLIN, B. M.; PEREYRA, M. A. Cultural History and Education. Critical Essays on Knowledge and Schooling. New York/Londres: RoutledgeFalmer, 2001.

\section{Notas}

${ }^{1}$ Cf. Gouvêa; Jinzenji (2006).

${ }^{2}$ Cf. Deleuze (1992, p. 109).

${ }^{3}$ O termo alquimia foi utilizado por Nietzsche a propósito da transvaloração de todos os valores e por Deleuze a propósito dos processos de individuação.

${ }^{4}$ Como sugere Alves (2003), sempre é possível escrever outras histórias sobre a relação singular entre cultura e cotidiano escolar, indicando as diferentes procedências da pesquisa na área.

${ }^{5}$ Larrosa (2001) faz essa mesma distinção ao afirmar que o que nos acontece (acontecimento) não se confunde com o que acontece (evento).

${ }^{6}$ Como apontado em Godoy (2008), via de regra, a prática permanece subordinada a uma sintaxe cujos possíveis já estão dados, a sintaxe entretém, desse modo, relações compensatórias ou complementares com a moldura cultural.

${ }^{7} \mathrm{O}$ meio deve ser entendido não somente como meio natural, mas como meio cultural, profissional, político e social.

${ }^{8}$ A extensa e variada bibliografia a respeito inclui desde artigos reunidos em diferentes livros resultantes da pesquisa ensejada pela Rede ACES, no período de 2002 a 2005, focada exclusivamente nas Instituições de Ensino Superior, como a produção técnica do 
Ministério da Educação e Cultura intitulada Mapeamento da Educaşão em Instituições Brasileiras de Educação Superior: elementos para políticas públicas, que faz referência à Rede ACES, e ainda a produção bibliográfica do campo alargado da Educação Ambiental em sua implicação com a formação, a pesquisa e o compromisso com a cidadania, seja no âmbito da educação formal seja no da não-formal.

${ }^{9}$ Embora seja de nosso conhecimento uma possível distinção entre racionalidade ambiental e racionalidade socioambiental (BOEIRA, 2002), consideramos que este artigo não seria o espaço adequado para nuançar essa distinção, até porque ambas servem aos propósitos de uma alquimia tal qual apresentada no início do texto.

Recebido: 30/03/09

Aprovado: 21/09/09

Contato:

Universidade Estadual de Campinas

Faculdade de Educação

Rua Bertrand Russel, 801

Cidade Universitária Zeferino Vaz

Campinas - SP

CEP 13083-865 